\title{
Mechanochemical Capture of Carbon Disulfide by Magnesium-carbon Composite
}

\author{
Bogu Liu, Qianqian Zhang, Pei Liu, Haipeng Chen, Hao Yu, Shixue Zhou \\ College of Chemical and Environmental Engineering, Shandong University of Science and Technology, 266590, Qingdao,
} China

\begin{abstract}
This work is concerned with mechanochemical capture of carbon disulfide $\left(\mathrm{CS}_{2}\right)$ by magnesium-carbon composite from ball-miling of $\mathrm{Mg}$ and carbonized anthracite. XRD analysis shows that cubic crystal MgS forms when milling time increases more than $1.0 \mathrm{~h}$. The sulfur contents in composites from $0.5,1.0,1.5$ and $2.0 \mathrm{~h}$ of milling are 1.35, 6.02, 9.62 and $11.69 \mathrm{wt} \%$, respectively. With the extension of milling time, the particle size of $\mathrm{Mg}$ decreases, while crystallite size of $\mathrm{MgS}$ shows an increase trend. The crystallite size of $\mathrm{MgS}$ in the composites from 1.0, 1.5 and 2 h of milling are 95, 132 and $275 \AA$, respectively. FT-IR analysis shows that there are four absorption peaks at $1210,1005,906$ and $764 \mathrm{~cm}^{-1}$, corresponding to the C-S bond absorption, are obvious, suggesting that the crystallitic carbon can deliver sulfur atoms during capture reaction. The mechanism of $\mathrm{CS}_{2}$ capture by composite is simulated by firstprinciples calculation, and the density of states and deformation charge density maps of $\mathrm{CS}_{2}$ adsorption on $\mathrm{Mg}(0001)$ suggest that the adsorption is chemisorption. This work can pave a new pathway for the absorption of $\mathrm{CS}_{2}$.
\end{abstract}

Keyword - Anthracite; Magnesium; Sulfur fixation; Mechanochemical

\section{I.INTRODUCTION}

Carbon disulfide $\left(\mathrm{CS}_{2}\right)$ is a sulfur source in chemicals as well as a solvent for polymers. It exists in natural gas, syngas from coal gasification ${ }^{[1]}$, and can lead to increase corrosion of the reactor and catalyst poisoning. There are three types of solution methods to remove $\mathrm{CS}_{2}$ : catalytic hydrolysis $\left.{ }^{[2,} 3\right]$, adsorption $^{[4,5]}$ and hydrodesulfurization ${ }^{[6,7]}$. The application of the above methods usually require high temperatures and catalysts, and the catalysts are easily inactivated due to long time of operation. In recent years, the developing absorbents with high sulfur capacity and high reaction activity have become a hot research topic, and magnesium is a promising candidate because of its abundant resource and low cost. Mechanochemical synthesis is an interesting technique that can drive a chemical reaction by shearing and impacting during milling.

Reactive milling as an excellent technique for the synthesis of various alloy phases including solid solutions, intermetallic, nano-crystalline and amorphous composites in large quantities has attracted worldwide interest in recent years ${ }^{[8,9]}$. Gattia et $\mathrm{al}^{[10]}$ investigated the influence of ball milling to $\mathrm{MgH}_{2} / \mathrm{Nb}_{2} \mathrm{O}_{5}$. Singh et al ${ }^{[11]}$ used ball milling to decrease the particle size of $\mathrm{CeO}_{2}$.

In this work, crystallitic carbon which prepared from anthracite coal by demineralization and carbonization was used to prepare $\mathrm{Mg}$-based composite by ball milling. The $\mathrm{Mg}$ - based composite was used to fix sulfur from $\mathrm{CS}_{2}$. The morphology, sulfur content and functional group of composites after milling were analyzed. The effect of milling time on the chemical reaction between $\mathrm{CS}_{2}$ and $\mathrm{Mg}$ powder was investigated. And the role of the crystallitic carbon during milling was discussed.

\section{EXPERIMENTAL}

Raw materials. Magnesium with purity $>99.5 \mathrm{wt} \%$ and particle size $<0.074 \mathrm{~mm}$ (Tianjin Ruijinte Chemical Company, China) was used as the basis of composite for sulfur fixation. The anthracite coal (Rujigou Mine, China) with low volatile matter content (6.60 wt\%, dry basis), low ash content $(8.55$ wt $\%)$, and high fixed carbon content ( $83.00 \mathrm{wt} \%)$ was used to prepare crystallitic carbon for composite formation with magnesium. The $\mathrm{CS}_{2}$ used for sulfur fixation test has an analytically purity (Chengdu Kelong Chemical Company, China). The $\mathrm{KOH}$ and $\mathrm{NaOH}$ used for coal demineralization have purities of $>90 \mathrm{wt} \%$ and $>98 \mathrm{wt} \%$ respectively, and the hydrochloric acid used is analytical reagent (Tianjin Dalu Chemical Regent Company, China), in which the $\mathrm{HCl}$ content was $36-38 \mathrm{wt} \%$.

Preparation of crystallitic carbon. The crystallitic carbon was prepared from anthracite coal by demineralization and carbonization treatment. The anthracite coal was demineralized to remove the mineral matter inherent in coal by alkaline melting and acid rinsing to an extent that the ash content was decreased to $0.05 \mathrm{wt} \%$ before carbonization. In the process of demineralization, the raw coal was crashed and ground to particle size less than $0.074 \mathrm{~mm}$, then mixed with the alkali which was the mixture of equal weight of $\mathrm{KOH}$ and $\mathrm{NaOH}$. The weight ratio of coal to alkali was 5:1. Next, the coal was heated at $400{ }^{\circ} \mathrm{C}$ for $1.5 \mathrm{~h}$, then the coal was soaked in hydrochloric acid of $4 \mathrm{wt} \% \mathrm{HCl}$ in a ratio of $1 \mathrm{~g}$ to $200 \mathrm{~mL}$ at $80{ }^{\circ} \mathrm{C}$ for $4 \mathrm{~h}$ in a thermostatic water bath. After demineralization, the coal was enclosed into a crucible, and carbonized at $1500{ }^{\circ} \mathrm{C}$ for $1 \mathrm{~h}$ in an electric resistance furnace with argon flow to protect the sample from being oxidized, and finally the crystallitic carbon of microcrystalline graphite structure was obtained.

Method of sulfur fixation. Crystallitic carbon and magnesium were put into the stainless vial with a weight ratio of 30:70. Then the vial was charged with $1.5 \mathrm{~mL} \mathrm{CS}_{2}$. Reactive milling was carried out on a ND7 planetary ball-mill 
(Nanda Tianzun Instrument Company, China). The milling media were stainless steel balls composed of 1000, 300, 30 and 3 balls of diameter 3,6, 10 and $20 \mathrm{~mm}$. The work revolution of the main axis was $180 \mathrm{r} / \mathrm{min}$.

Characterization methods. The morphology observation of composite was performed on a Hitachi S-570 scanning electron microscope (SEM) operating at $20 \mathrm{kV}$. The crystal structure of the composite was determined by Rigaku D/MaxrB X-ray diffractometer (XRD) operating at a scanning speed of $10 \%$ min and in steps of $0.02^{\circ}$ with $\mathrm{Cu} \mathrm{K \alpha}$ radiation. The sulfur content of the composite after reaction with sulfur compound was tested by trace sulfur analyzer of ZXL8 (Hebi Zhisheng Technology Company). The functional groups of the composite were determined by a Nicolet 380 Fourier transform infrared spectroscope (FT-IR).

Parameters for calculation. The structure and energy calculations were based on density functional theory (DFT) by the Materials Studio 7.0 software (Accelrys Software Incorporation). The generalized gradient approximation (GGA) parameterized by Perdewe-Burkee-Ernzerhof (PBE) was adopted as the exchange-correction functions in the calculation. The convergence criteria used was energy of $2.0 \times 10^{-5} \mathrm{Ha}$, force of $0.004 \mathrm{Ha} / \mathrm{nm}$ and displacement of 0.0005 $\mathrm{nm}$. A regular mesh of $(4 \times 2 \times 1) \mathrm{k}$-points was used to sample the Brillouin zone for the supercells. The smearing energy was set as $0.005 \mathrm{Ha}$ to realize the rapid energy convergence.

\section{RESULTS AND DISCUSSION}

Sulfur content analysis. Sulfur contents of samples from different milling time are shown in Table 1. The sulfur contents of different composites show an increase trend with the extension of milling time. The composite from $0.5 \mathrm{~h}$ milling has low sulfur content with an average value of $1.35 \%$. The sulfur content increased to $11.69 \%$ with the milling time extended to $2.0 \mathrm{~h}$. This means ball milling can fix $\mathrm{CS}_{2}$ to the composite. The particle size of magnesium will decrease and the amount of surface defect will increase with the extension of milling time, so that more $\mathrm{CS}_{2}$ can be fixed to magnesium with the increase of milling time.

TABLE 1. Sulfur content of samples from different milling time

\begin{tabular}{|c|c|c|c|c|c|}
\hline Milling time (h) & $\mathrm{CS}_{2}(\mathrm{~mL})$ & $\operatorname{Mg}(g)$ & $C(g)$ & Sample volume (g) & Sulfur content (wt $\%)$ \\
\hline \multirow{2}{*}{0.5} & \multirow{2}{*}{1.5} & \multirow{2}{*}{7} & \multirow{2}{*}{3} & 0.0200 & 1.38 \\
\hline & & & & 0.0200 & 1.31 \\
\hline \multirow{2}{*}{1.0} & \multirow{2}{*}{1.5} & \multirow{2}{*}{7} & \multirow{2}{*}{3} & 0.0206 & 5.98 \\
\hline & & & & 0.0205 & 6.05 \\
\hline \multirow{2}{*}{1.5} & \multirow{2}{*}{1.5} & \multirow{2}{*}{7} & \multirow{2}{*}{3} & 0.0200 & 9.61 \\
\hline & & & & 0.0206 & 9.63 \\
\hline \multirow{2}{*}{2.0} & \multirow{2}{*}{1.5} & \multirow{2}{*}{7} & \multirow{2}{*}{3} & 0.0203 & 11.72 \\
\hline & & & & 0.0205 & 11.65 \\
\hline
\end{tabular}

Morphology observation. The morphologies from SEM observation of the composites from different milling time are shown in Fig. 1. The particle size distribution of the composites from different milling time is different. $\mathrm{Mg}$ powders are usually difficult to be milled into nanoscale because of its cold welding during milling. The crystallitic carbon can prevent $\mathrm{Mg}$ powders from cold welding effectively. In addition, crystallite carbon is usually with sharp edges, so it could play a role of milling media to decrease $\mathrm{Mg}$ layers. After $0.5 \mathrm{~h}$ milling, the particle size of the composite is in the range of 1-2 $\mu \mathrm{m}$, as shown in Fig. 1 (a). And the particle size will decrease to $800 \mathrm{~nm}$ when the milling time increases to $1.0 \mathrm{~h}$, as shown in Fig. 1 (b). As the milling time up to 1.5 $\mathrm{h}$, the majority of the particles are less than $1 \mu \mathrm{m}$ which is shown in Fig.1 (c). Finally, as the milling time increases to 2.0 $\mathrm{h}$, the particles further decreases and powder agglomeration becomes more apparent, as shown in Fig. 1 (d).
Functional group analysis. The crystallitic carbon can react with $\mathrm{CS}_{2}$ to produce $\mathrm{C}-\mathrm{S}$ functional group during ball milling. Fig. 2 is the FT-IR spectra of the raw carbon and composite from $0.5,1.0,1.5$ and $2.0 \mathrm{~h}$ milling. The FT-IR spectrum of the composite from $0.5 \mathrm{~h}$ of milling is similar to that of the raw carbon. This means carbon cannot react with $\mathrm{CS}_{2}$ during $0.5 \mathrm{~h}$ of milling. When the milling time increases over $1.0 \mathrm{~h}$, the absorption peaks of C-S at 1210, 1005, 906 and $764 \mathrm{~cm}^{-1}$ in the FT-IR spectra. With the increasing of milling time, the absorption peaks of $\mathrm{C}=\mathrm{S}$ and $\mathrm{S}-\mathrm{O}$ become more obvious, which means that $\mathrm{CS}_{2}$ can chemically absorb on the surface of crystallitic carbon with abundant surface dangling bonds. 

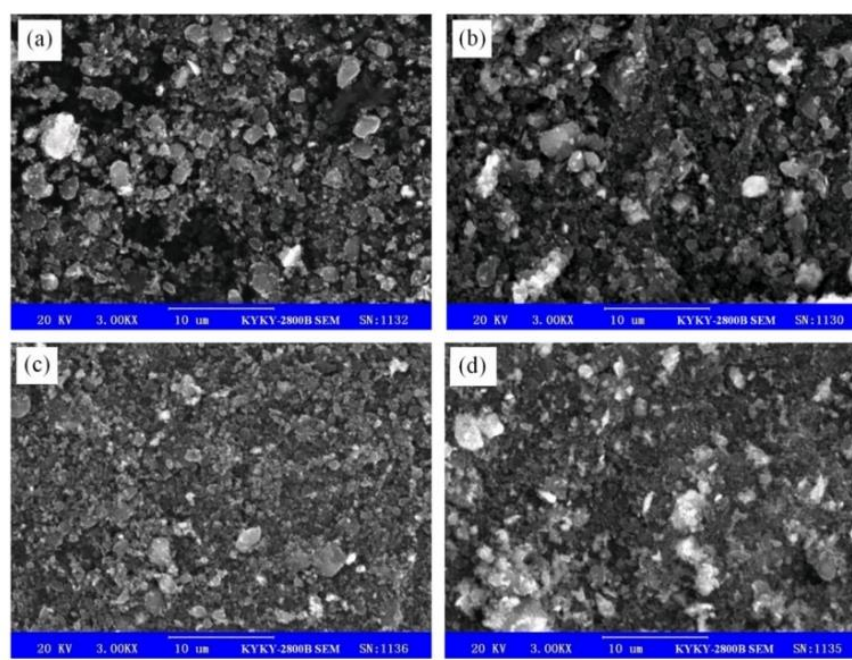

Fig. 1 SEM images of the composite from $0.5 \mathrm{~h}$ (a), $1.0 \mathrm{~h} \mathrm{(b),}$ $1.5 \mathrm{~h}(\mathrm{c})$ and $2.0 \mathrm{~h}(\mathrm{~d})$ of milling

Crystalline structure. The crystalline phases in the powders after milling can be identified by XRD analysis as shown in Fig. 3. The XRD pattern of the composite milled 0.5 $\mathrm{h}$ has no $\mathrm{MgS}$ diffraction peaks, which means $\mathrm{CS}_{2}$ and $\mathrm{Mg}$ cannot react, as shown in Fig. 3 (a). The MgS appears when the milling time increases over $1.0 \mathrm{~h}$. It suggests that the $\mathrm{S}$ atom entered the crystal lattice of $\mathrm{Mg}$ and formed $\mathrm{MgS}$. The surface energy of $\mathrm{Mg}$ is enhanced due to the decreasing particle size of $\mathrm{Mg}$ with the increasing of milling time, and therefore $\mathrm{CS}_{2}$ can react with the $\mathrm{Mg}$ more easily.

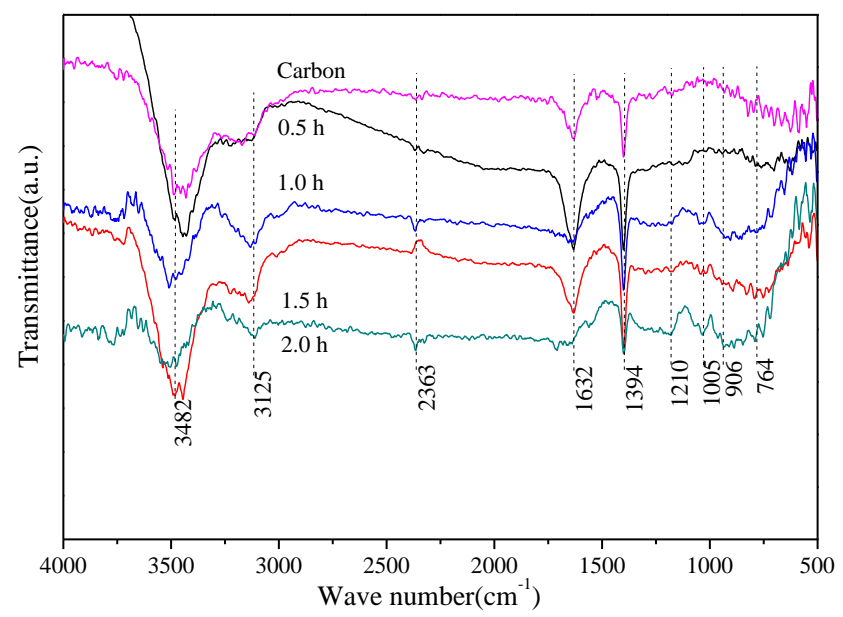

Fig. 2 FT-IR spectra of the raw carbon and composite from 0.5 $\mathrm{h}, 1.0 \mathrm{~h}, 1.5 \mathrm{~h}$ and $2.0 \mathrm{~h}$ of milling

The spacing distance of the crystal plane $(d)$ and crystal size $(L)$, based on XRD analysis of the composite from different milling time, are listed in Table 2. The size of the $\operatorname{MgS}(220)$ plane is 95,132 and $275 \AA$ from $1.0,1.5$ and $2.0 \mathrm{~h}$ of milling, respectively. The crystal size of the $\mathrm{MgS}$ is increased with the increase of milling time. For $\mathrm{Mg}$, the crystal size of all planes decreases with the increase of milling time. It suggests that ball milling can decrease the crystal size of $\mathrm{Mg}$.
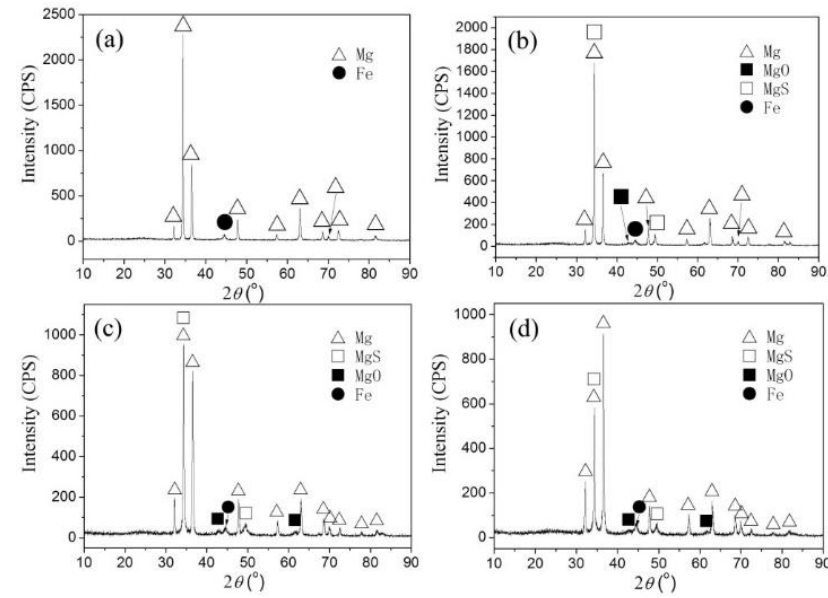

Fig. 3 XRD patterns of the composites from $0.5 \mathrm{~h}(\mathrm{a}), 1.0 \mathrm{~h}$ (b), $1.5 \mathrm{~h} \mathrm{(c)} \mathrm{and} 2.0 \mathrm{~h}(\mathrm{~d})$ of milling

First-principles calculation. Magnesium is hexagonal close packing and the unit cell as shown in Fig. 4 (b). The $\operatorname{Mg}\left(\begin{array}{llll}0 & 0 & 0 & 1\end{array}\right)$ plane has four different adsorption sites as shown in Fig. 4 (c). The adsorption energy of $\mathrm{CS}_{2}$ on different sites of $\operatorname{Mg}\left(\begin{array}{llll}0 & 0 & 0 & 1\end{array}\right)$ plane is calculated by equation (1).

$$
E_{\text {ads }}=E_{\mathrm{CS}_{2} / \mathrm{Mg}_{(0001)}}-E_{\mathrm{CS}_{2}}-E_{\mathrm{Mg}_{(0001)}}
$$

$E_{\text {ads }}$ in the equation is the adsorption energy of $\mathrm{CS}_{2}$. $E_{\mathrm{CS} 2 / \mathrm{Mg}\left(\begin{array}{lll}0 & 0 & 0\end{array}\right)}$ is the total energy of the $\mathrm{Mg}\left(\begin{array}{llll}0 & 0 & 0 & 1\end{array}\right)$ plane after $\mathrm{CS}_{2}$ adsorption. $E_{\mathrm{CS} 2}$ is the energy of $\mathrm{CS}_{2}$ molecule. And $E_{\mathrm{Mg}(0}$ $\left.\begin{array}{lll}0 & 0 & 1\end{array}\right)$ is the energy of the clean $\operatorname{Mg}\left(\begin{array}{llll}0 & 0 & 0 & 1\end{array}\right)$ plane. The adsorption energy data of $\mathrm{CS}_{2}$ on fcc, hcp, top and bridge sites of $\operatorname{Mg}\left(\begin{array}{llll}0 & 0 & 0 & 1\end{array}\right)$ plane are $-82.39,-82.21,-73.22$ and -40.68 $\mathrm{kJ} / \mathrm{mol}$ respectively. It suggests that the adsorption of $\mathrm{CS}_{2}$ on fcc, hcp and top sites of $\operatorname{Mg}\left(\begin{array}{llll}0 & 0 & 0 & 1\end{array}\right)$ plane is chemisorption, and it is physical adsorption when $\mathrm{CS}_{2}$ adsorbs at bridge site.

The initial and finial states of $\mathrm{CS}_{2}$ adsorption on fcc, hcp, top and bridge sites of $\operatorname{Mg}\left(\begin{array}{llll}0 & 0 & 0 & 1\end{array}\right)$ are shown in Fig. 5. The molecular structure of $\mathrm{CS}_{2}$ is changed obviously when $\mathrm{CS}_{2}$ adsorbed on fcc, hcp and top site of $\operatorname{Mg}\left(\begin{array}{llll}0 & 0 & 0 & 1\end{array}\right)$ surface. The bond angles of S-C-S change from $180^{\circ}$ to $146.2^{\circ}, 147.4^{\circ}$, $151.2^{\circ}$ and $179.3^{\circ}$ on fcc, hcp, top and bridge sites, respectively. Fig. 6 is the DOS (density of states) and deformation charge density maps of $\mathrm{CS}_{2}$ adsorption on fcc site

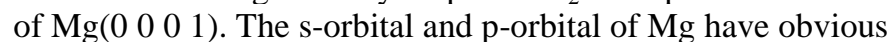
overlap with s-orbital of $\mathrm{C}$ and s-orbital and p-orbital of $\mathrm{S}$ at $0.32 \mathrm{Ha}$. The s-orbital and p-orbital of $\mathrm{Mg}$ have obvious overlap with p-orbital of $\mathrm{C}$ and s-orbital of $\mathrm{S}$ at $-0.53 \mathrm{Ha}$. And the s-orbital and p-orbital of $\mathrm{Mg}$ have obvious overlap with sorbital of $\mathrm{C}$ and s-orbital of $\mathrm{S}$ at $-0.61 \mathrm{Ha}$. This means that the $\mathrm{CS}_{2}$ adsorption on $\mathrm{Mg}$ is chemisorption. 
TABLE 2. Crystalline data from XRD analysis of the samples from different milling time

\begin{tabular}{|c|c|c|c|c|c|c|c|c|c|c|}
\hline \multirow{2}{*}{ Crystal plane } & \multirow{2}{*}{ 2-Theta/Deg } & \multirow{2}{*}{$d / \AA$} & \multicolumn{2}{|c|}{$0.5 \mathrm{~h}$} & \multicolumn{2}{c|}{$1.0 \mathrm{~h}$} & \multicolumn{2}{c|}{$1.5 \mathrm{~h}$} & \multicolumn{2}{c|}{$2.0 \mathrm{~h}$} \\
\cline { 4 - 11 } & & & FWHM & $L / \AA$ & FWHM & $L / \AA$ & FWHM & $L / \AA$ & FWHM & $L / \AA$ \\
\hline $\mathrm{Mg}(100)$ & 32.13 & 2.78 & 0.193 & 600 & 0.174 & 579 & 0.247 & 366 & 0.246 & 368 \\
\hline $\mathrm{Mg}(002)$ & 34.37 & 2.60 & 0.168 & 814 & 0.146 & 782 & 0.177 & 567 & 0.211 & 446 \\
\hline $\mathrm{Mg}(101)$ & 36.58 & 2.45 & 0.185 & 539 & 0.187 & 530 & 0.226 & 414 & 0.238 & 387 \\
\hline $\mathrm{Mg}(102)$ & 47.76 & 1.90 & 0.207 & 578 & 0.188 & 547 & 0.233 & 412 & 0.275 & 340 \\
\hline $\mathrm{MgS}(220)$ & 49.45 & 1.84 & $/$ & $/$ & 0.923 & 95 & 0.669 & 132 & 0.333 & 275 \\
\hline $\mathrm{Mg}(110)$ & 57.34 & 1.60 & 0.239 & 416 & 0.288 & 335 & 0.333 & 285 & 0.334 & 284 \\
\hline $\mathrm{Mg}(103)$ & 63.04 & 1.47 & 0.225 & 464 & 0.233 & 442 & 0.273 & 367 & 0.292 & 340 \\
\hline $\mathrm{Mg}(112)$ & 68.61 & 1.36 & 0.252 & 616 & 0.199 & 559 & 0.305 & 333 & 0.348 & 288 \\
\hline
\end{tabular}
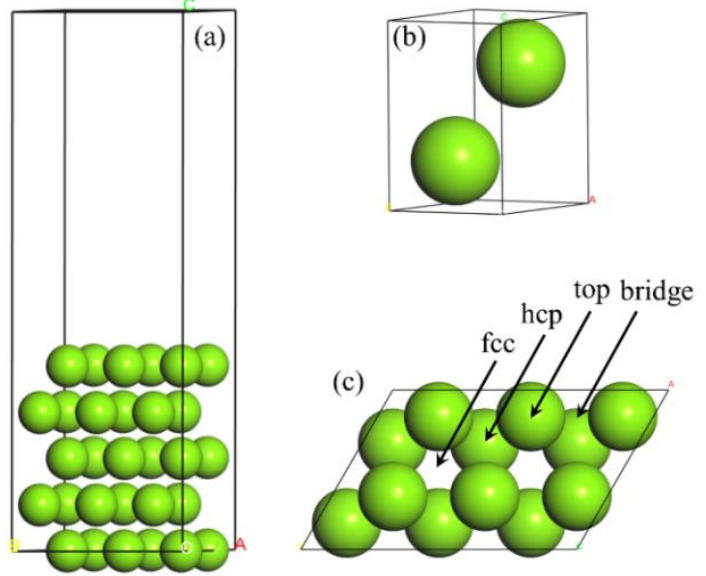

Fig. 4 Supercell of the $\mathrm{Mg}\left(\begin{array}{llll}0 & 0 & 0 & 1\end{array}\right)$ (a), Mg cell (b) and adsorption sites on $\mathrm{Mg}\left(\begin{array}{llll}0 & 0 & 0 & 1\end{array}\right)$ (c)

\section{IV.CONCLUSION}

$\mathrm{Mg}$ can react with $\mathrm{CS}_{2}$ to form $\mathrm{MgS}$ during ball milling, by which sulfur fixation can be realized. The crystallitic carbon plays roles of milling media and dispersive agent for the reduction of $\mathrm{Mg}$ particles, and therefore the $\mathrm{Mg}$ particles are easily milled to less than $1 \mu \mathrm{m}$, which is in favor of its reaction with $\mathrm{CS}_{2}$. On the FT-IR spectra, there are four absorption peaks at 1210, 1005, 906 and $764 \mathrm{~cm}^{-1}$, which are consistent with the absorption peaks of $\mathrm{C}-\mathrm{S}$ bond. It indicates that the crystallitic carbon also has a function of delivering $\mathrm{S}$ atoms during the reaction of $\mathrm{Mg}$ and $\mathrm{CS}_{2}$. The resulted $\mathrm{MgS}$ is of cubic crystal structure and its crystal domain size increases with the increase of sulfur content from the extension of milling time. The DOS and deformation charge density maps show that the adsorption of $\mathrm{CS}_{2}$ on $\mathrm{Mg}$ surface is chemisorption.

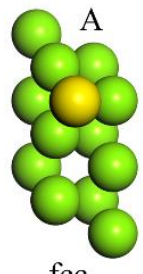

fcc

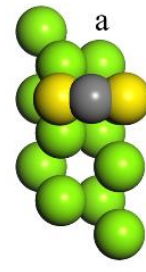

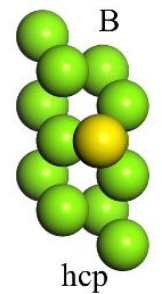

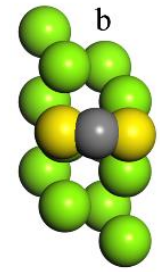

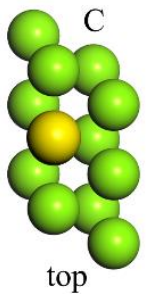

top

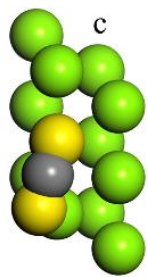

$\mathrm{D}$

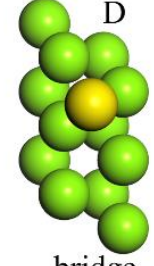

bridge

d

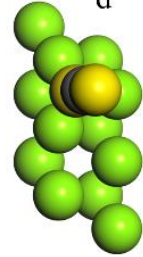

Fig. 5 Initial and finial state of $\mathrm{CS}_{2}$ adsorption on fcc, hcp, top and bridge sites of $\mathrm{Mg}(0001)$

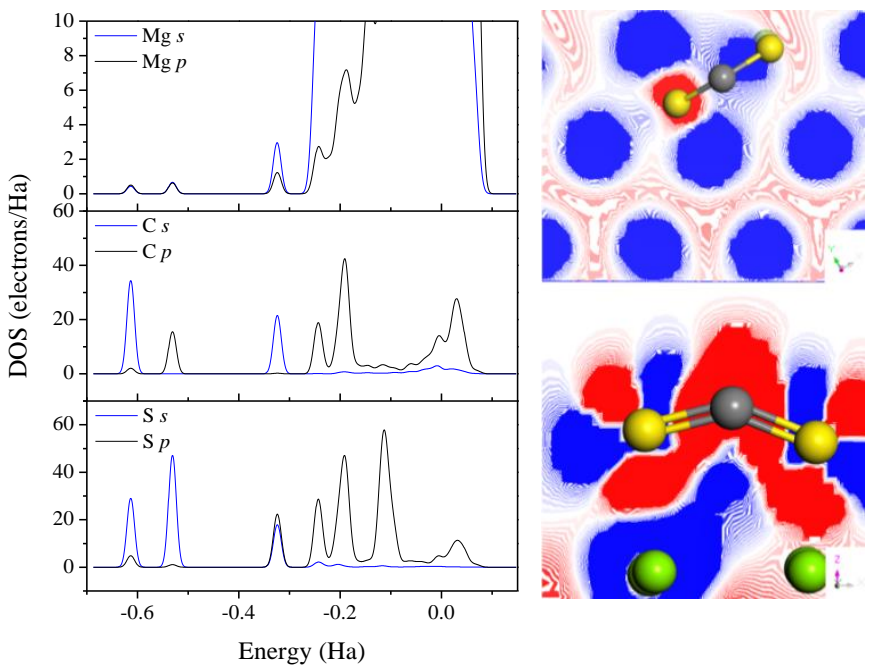

Fig. 6 DOS (a) and deformation charge density maps (b) of $\mathrm{CS}_{2}$ adsorption on fcc site of $\mathrm{Mg}(0001)$ 


\section{ACKNOWLEDGEMENTS}

This work is executed at financial support of the State represented by the Ministry of Education and Science of the RF carried out within implementation of the Federal target program 'Researches and Development on the Priority Directions of Development of Scientific and Technological Complex of Russia for 2014-2020' under the Agreement on Granting a Subsidy \#14.583.21.0004 as of 16 July 2014. The unique identifier for scientific research (project) RFMEFI58314X0004. Besides, the work is supported by the National Natural Science Foundation of China (No. 21176145) and Shenzhen Supercomputer Center of China.

\section{REFERENCES}

[1] K. Zhang, Y. Liu, S. Tian, E. Zhao, J. Zhang, C. Liu, Preparation of bifunctional $\mathrm{NiPb} / \mathrm{ZnO}$-diatomite-ZSM-5 catalyst and its reactive adsorption desulfurization coupling aromatization performance in FCC gasoline upgrading process, Fuel, 104 (2013) 201-207

[2] D. He, H. Yi, X. Tang, P. Ning, K. Li, H. Wang, S. Zhao, The catalytic hydrolysis of carbon disulfide on $\mathrm{Fe}-\mathrm{Cu}-\mathrm{Ni} / \mathrm{AC}$ catalyst at low temperature, Journal of Molecular Catalysis A: Chemical, 357 (2012) 4449

[3] H. Yi, D. He, X. Tang, H. Wang, S. Zhao, K. Li, Effects of preparation conditions for active carbon-based catalyst on catalytic hydrolysis of carbon disulfide, Fuel, 97 (2012) 337-343.

[4] J. Yang, P. Juan, Z. Shen, R. Guo, J. Jia, H. Fang, Y. Wang, Removal of carbon disulfide $\left(\mathrm{CS}_{2}\right)$ from water via adsorption on active carbon fiber (ACF), Carbon, 44 (2006) 1367-1375.

[5] Z. Xie, J. Li, N. Zhao, F. Wang, W. Peng, B. Mao, F. Xiao, W. Wei, Y. Sun, The adsorption of carbon disulfide on activated carbon fibers, New Carbon Materials, 24 (2009) 260-264
[6] E.K. Novakova, L. McLaughlin, R. Burch, P. Crawford, K. Griffin, C. Hardacre, P. Hu, D.W. Rooney, Palladium-catalyzed liquid-phase hydrogenation/hydrogenolysis of disulfides, Journal of Catalysis, 249 (2007) 93-101.

[7] L. McLaughlin, E. Novakova, R. Burch, C. Hardacre Hydrogenation/hydrogenolysis of disulfides using sulfided $\mathrm{Ni} / \mathrm{Mo}$ catalysts, Applied Catalysis A: General, 340 (2008) 162-168.

[8] H. Chen, H. Yu, Q. Zhang, B. Liu, P. Liu, X. Zhou, Z. Han, S. Zhou, Enhancement in dehydriding performance of magnesium hydride by iron incorporation: A combined experimental and theoretical investigation, J. Power Sources, 322 (2016) 179-186.

[9] K. Suárez-Alcántara, A.F. Palacios-Lazcano, T. Funatsu, J.G. CabañasMoren, Mg-M-LiH alloys prepared by mechanical milling and their hydrogen storage characteristics, Int. J. Hydrogen Energy 40 (2015) 17344-17353.

[10] D.M. Gattia, A. Montone, L. Pasquini, Microstructure and morphology changes in $\mathrm{MgH}_{2}$ /expanded natural graphite pellets upon hydrogen cycling, International Journal of Hydrogen Energy, 38 (2013) 1918-1924.

[11] R.K. Singh, T. Sadhasivam, G.I. Sheeja, P. Singh, O.N. Srivastava, Effect of different sized $\mathrm{CeO}_{2}$ nano particles on decomposition and hydrogen absorption kinetics of magnesium hydride, International Journal of Hydrogen Energy, 38 (2013) 6221-6225. 